\title{
Laparoscopically assisted colorectal surgery provides better short-term clinical and inflammatory outcomes compared to open colorectal surgery
}

\author{
Jurij Janež ${ }^{1}$, Tina Korać2 ${ }^{2}$ Anamarija Rebolj Kodre ${ }^{3}$, Franc Jelenc ${ }^{1}$, Alojz Ihan²
}

\author{
${ }^{1}$ Department of Abdominal Surgery, University Medical Centre, Ljubljana, Slovenia \\ ${ }^{2}$ Institute of Microbiology and Immunology, Faculty of Medicine, \\ University of Ljubljana, Ljubljana, Slovenia \\ Institute for Biostatistics and Medical Informatics, Faculty of Medicine, \\ University of Ljubljana, Ljubljana, Slovenia
}

Submitted: 18 April 2013

Accepted: 26 January 2014

Arch Med Sci 2015; 11, 6: 1217-1226

DOI: 10.5114 /aoms.2015.56348

Copyright @ 2015 Termedia \& Banach

\section{Abstract}

Introduction: Changes in immune function after surgery may influence overall outcome, length of hospital stay, susceptibility to infection and perioperative tumour dissemination in cancer patients. Our aim was to elaborate on postoperative differences in the immune status and the intensity of the systemic inflammatory response between two groups of prospectively enrolled patients with colorectal cancer, namely patients undergoing laparoscopically assisted or open colorectal surgery.

Material and methods: Blood samples from 77 patients were taken before surgery and then $3 \mathrm{~h}, 24 \mathrm{~h}$ and 4 days after surgery. The inflammatory response was determined by leukocyte counts, erythrocyte sedimentation rate (ESR), C-reactive protein (CRP) and procalcitonin levels (PCT). Immune status was determined by phenotypic analysis of lymphocyte populations and the activation of mononuclear cells. CD64 expression and cytokine expression were also determined.

Results: Patients undergoing laparoscopically assisted surgery had less intraoperative blood loss $(p=0.002)$, earlier resumption of diet $(p=0.002)$ and shorter hospital stay $(p=0.02)$. Numbers of total leukocytes $(p=0.12)$, CRP $(p=0.002)$ and PCT $(p=0.23)$ were remarkably higher 4 days after surgery in patients who underwent an open colorectal procedure. There was an important decrease in monocyte HLA-DR expression $3 \mathrm{~h}$ after surgery in patients undergoing laparoscopically assisted surgery $(p=0.03)$.

Conclusions: Our study suggests that minimally invasive surgery provides better short-term clinical outcomes for patients with resectable colorectal cancer. The acute inflammatory response is less pronounced. Post-surgical immunological disturbance in both groups is similar, but we observed a divergent effect of different surgical approaches on the expression of HLA-DR on monocytes. However, our results corroborate the results of previous studies.

Key words: laparoscopic surgery, cancer of colon and rectum, immune status.

\section{Introduction}

Colorectal cancer remains one of the most commonly diagnosed malignancies worldwide. Surgical therapy, often combined with radiotherapy and chemotherapy, still provides the best outcomes for these
Corresponding author:

Jurij Janež

Department

of Abdominal Surgery

University Medical Centre

Zaloška cesta 7

1525 Ljubljana, Slovenia

Phone: +38651315815

E-mail: jurij.janez@gmail.com 
patients and therefore remains the treatment of choice. Minimally invasive procedures are gaining more recognition and have developed into good alternative approaches to conventional open surgery, even in cancer surgery $[1,2]$. There has been extensive research in the past decade comparing laparoscopically assisted surgery (LAS) and conventional open colorectal surgery (OCS), mainly observing short-term clinical benefits, faster recovery and increased patients' postoperative quality of life following minimally invasive procedures [3-7]. Studies observing long-term outcomes have shown that carcinoma recurrence rates after laparoscopic resection are no different from those after open type surgery [8-10].

It has long been known that surgery itself has important immune consequences in terms of temporary suppression of the immune system, which is shown in depleted numbers of $T$ lymphocytes, B lymphocytes and natural killer (NK) cells [11-15]. A variety of immune parameters seem to be better preserved in minimally invasive methods compared to equivalent open surgical procedures. Following conventional surgery there is more severe temporary suppression of immune cells in innate and specific immunity [16], better preservation of neutrophil function [17], and a more pronounced increase in the total number of leukocytes [18]. Cellular cytokine production seems to be better preserved after laparoscopic procedures, while cytokine plasma levels are significantly higher after conventional surgery [18]. Some authors observed down-regulation of the T-helper cell type 1 response (a decrease in IFN- $\gamma$, TNF- $\alpha$, and IL-2 production) after conventional surgery but not after a minimally invasive procedure [19]. Overall, minimally invasive surgery usually causes less immunological disturbance [18, 20, 21]. Consequently, laparoscopic surgery can be performed with faster recovery, less postoperative pain and shorter hospital stay [6]. Decreased perioperative stress may be particularly important for cancer patients, since there is a higher likelihood of tumour dissemination in the early postoperative period due to changes in the patient's immune system [22]. While most authors agree that the cell-mediated immune response is better preserved after laparoscopic surgery [21, 23, 24], others have found no difference when comparing the cellular immune response [25], number and function of NK cells or monocyte HLA-DR expression $[14,25,26]$. Wichmann et al. suggest that the nonspecific immune response is less affected by laparoscopic surgery when compared with open surgery while the specific cell-mediated immunity is equally affected [20].

Due to conflicting data, our goal was to elaborate on the immunological effects in both types of surgery and evaluate the intensity of the sys- temic inflammatory response in colorectal cancer patients by comparing a variety of immune parameters, further exploring the activation of mononuclear cells and the role of the early sepsis marker CD64. We hypothesised that minimally invasive surgery results in reduced postoperative immune dysfunction and a reduced postoperative systemic inflammatory response.

\section{Material and methods}

\section{Patients and surgery}

Initially 77 adult patients were included in our non-randomized prospective study. All of them met the primary inclusion criteria: they were diagnosed with primary cancer of the colon or upper third of the rectum and were treated at the Clinical Department of Abdominal Surgery, University Medical Centre Ljubljana, between June 2011 and May 2012. The study design was explained to all potential participants and it was necessary to sign an informed consent form. Patients with the following conditions were excluded from the study: emergency operation due to tumour-related intestinal obstruction or perforation, suspected intra-abdominal abscess seen on preoperative imaging studies, inflammatory bowel disease (Crohn's disease, ulcerative colitis or any other nonspecific inflammatory bowel disease), previously or synchronously diagnosed malignant disease, advanced primary disease (metastatic disease or locally advanced tumour), receiving immunosuppressive therapy, or with known immunodeficiency (HIV, lymphoma, leukaemia). Patients with anastomotic leak or major postoperative intra-abdominal bleeding prior to the last evaluation (day 4 after surgery) who needed blood transfusion or surgical intervention were excluded from our study as well, since anastomotic leak or major intra-abdominal bleeding with surgical intervention is associated with much greater risk of developing a systemic inflammatory response (SIRS) and blood transfusion is associated with depression of the immune system $[27,28]$.

The study protocol was approved by the Commission of the Slovenian Medical Ethics Committee.

Eligible patients were consecutively enrolled in our study and they were divided into two groups. The first group of patients underwent open colorectal surgery (OCS group) and the second group laparoscopically assisted surgery (LAS group). On hospital admission, demographics, nutritional status with body mass index, presence of comorbidity factors (Table I) and primary diagnosis were recorded in all patients. In addition to data regarding the surgical procedure and postoperative course, we collected the parameters of histological findings. All patients received antibiotic prophylaxis with a single dose of gentamicin and metronidazole before the induction of anaesthesia. 
Table I. Demographic, epidemiological, surgical and pathological characteristics of enrolled patients

\begin{tabular}{|c|c|c|c|}
\hline \multirow[t]{2}{*}{ Variable } & \multicolumn{2}{|c|}{ Surgery type } & \multirow[b]{2}{*}{ Value of $p$} \\
\hline & Open $(n=34)$ & Laparoscopic $(n=41)$ & \\
\hline Age [years] & $67(11.7)$ & $63(12.3)$ & $0.12 *$ \\
\hline Gender: & & & $0.08^{*}$ \\
\hline Male & $13(38)$ & $24(59)$ & \\
\hline Female & $21(62)$ & $17(41)$ & \\
\hline Final histology: & & & $0.74^{\star}$ \\
\hline Adenocarcinoma & $30(88)$ & $34(83)$ & \\
\hline Adenomas & $4(12)$ & $7(17)$ & \\
\hline Staging: & & & $0.06^{\star}$ \\
\hline 0 & 0 & $2(6)$ & \\
\hline I & $10(29)$ & $13(38)$ & \\
\hline$\|$ & $11(32)$ & $7(21)$ & \\
\hline III & $8(24)$ & $11(32)$ & \\
\hline IV & 0 & $1(3)$ & \\
\hline Unknown & $5(15)$ & 0 & \\
\hline Vascular invasion: & & & 0.32 \\
\hline No & $25(78)$ & $32(80)$ & \\
\hline Yes & $2(6)$ & 0 & \\
\hline Lymphangiosis carcinomatosa & $5(16)$ & $8(20)$ & \\
\hline Perineural invasion & $2(6)$ & $3(8)$ & $1 *$ \\
\hline Comorbidities: & & & $1^{*}$ \\
\hline Arterial hypertension & $14(41)$ & $17(41)$ & \\
\hline Hyperlipidemia & $5(15)$ & $7(17)$ & \\
\hline Diabetes mellitus & $2(6)$ & $6(15)$ & \\
\hline Benign prostatic hypertrophy & $5(15)$ & $2(5)$ & \\
\hline Osteoporosis & $1(3)$ & $1(2)$ & \\
\hline Psoriasis & $1(3)$ & 0 & \\
\hline Chronic pulmonary disease & $2(6)$ & $4(10)$ & \\
\hline Chronic atrial fibrillation & $2(6)$ & $7(17)$ & \\
\hline Hemicolectomy type: & & & $1 *$ \\
\hline Left & $11(32)$ & $13(32)$ & \\
\hline Right & $15(44)$ & $18(44)$ & \\
\hline Anterior resection of the rectum & $8(24)$ & $10(24)$ & \\
\hline Number of lymph nodes & $16.8(9.0)$ & $14.7(9.5)$ & $0.42^{*}$ \\
\hline \multicolumn{4}{|l|}{ Resection margin status: } \\
\hline Closest intestinal margin & $5.9(3.1)$ & & \\
\hline Radial margin & $2.0(1.1)$ & & \\
\hline
\end{tabular}

Results presented as $n(\%)$ 
The anastomosis was performed intracorporeally in the LAS group. An extracorporeal handsewn or stapled anastomosis was made in patients who underwent laparoscopically assisted right hemicolectomy. The anastomosis in the open surgery group was hand-sewn except for patients who underwent low anterior resection of the rectum. Pneumoperitoneum was induced by insufflation of $\mathrm{CO}_{2}$ and was maintained around $12 \mathrm{~mm} \mathrm{Hg}$ during the entire surgical procedure.

All patients had a mechanical bowel preparation with polyethylene glycol (PEG) solution the day before surgery.

There were seven surgeons performing both types of operations. All surgeons had completed their learning curve (performing at least 100 laparoscopically assisted and open procedures) and were considered equally trained in both procedures.

Conversion to an open procedure was at the discretion of the surgeon and was defined as a need to perform an abdominal incision longer than $7 \mathrm{~cm}$. Conversions to an open procedure were made because of unclear anatomical relations, laparoscopically inoperable disease, laparoscopically uncontrollable bleeding or adhesions from previous operations.

Oral food intake was also initiated at the discretion of the surgeon. Postoperative pain was objectively assessed by evaluation of the total number of days during which narcotics, administered intravenously, were needed. The length of hospital stay was defined as days after the operation until discharge home.

Perioperative mortality was defined as death occurring within 30 days of operative resection. Follow-up was obtained by physician's charts.

\section{Blood samples}

Peripheral venous blood samples were taken from all patients before surgery and then $3 \mathrm{~h}, 24 \mathrm{~h}$ and 4 days after surgery. The postoperative systemic inflammatory response was determined by leukocyte counts, C-reactive protein (CRP), procalcitonin (PCT) and erythrocyte sedimentation rate (ESR). Additional blood samples were collected in EDTA collection tubes to determine the immune status of the patients after surgery on the basis of phenotypic analysis of leukocyte populations and the activation of mononuclear cells by flow cytometry. Absolute numbers of $\mathrm{T}$ and $\mathrm{B}$ lymphocytes were measured, followed by determining the helper T cells (CD4+), cytotoxic T cells (CD8+), natural killer cells (CD16+CD56+), activated $T$ cells, HLA-DR+ monocytes, CD16+CD14+ monocytes, CD16+ granulocytes and CD14+ monocytes. Lymphocytes were analysed for the expression of cell surface antigens using the following combinations of monoclonal antibodies and fluorescent labels: CD3-PE, CD4-PerCP, CD8-FITC, CD19-FITC, CD56-PE, all from Cytognos (Salamanca, Spain) and HLA-DR-PE, CD14-PerCP, CD16-FITC, all from Becton Dickinson Biosciences (Oxford, UK).

The samples were prepared by adding $10 \mu \mathrm{l}$ of appropriate monoclonal antibodies to $50 \mu \mathrm{l}$ of whole blood and incubating in the dark. After incubation, the erythrocytes were lysed and fixed according to the manufacturers' instructions. The fluorescence was measured with a FACSCanto cytometer (BD Biosciences Pharmingen, San Diego, CA USA) using acquisition and analysis software. The lymphocyte populations were automatically gated. The levels of HLA-DR, CD14 and CD16 expression were assessed as their intensities, based on the arithmetic mean fluorescence intensity (MFI).

Expression of CD64 was analysed using the Leuko64 assay (Trillium Diagnostics, LLC, Maine, USA) according to the manufacturer's instructions. CD64 index measurements were derived from the ratio of linearized MFI of the cell populations and the FITC signal from the beads. An internal negative control of the assay was provided by the automated measurement of the lymphocyte CD64 index $(<1.0)$, while the internal positive control of the assay was provided by automated measurement of the monocyte CD64 index (> 3.0).

The serum IL-6, IL-10, IL-8, TNF, IL-1 $1 \beta$ and IL12 p70 levels were determined from sera with flow-cytometry, using the Cytometric Bead Array (Human Inflammatory Cytokine Kit, BD Biosciences Pharmingen, San Diego, CA USA).

\section{Statistical analysis}

The statistical language $R$ was used to analyse the data ( $R$ version 3.0, $R$ Foundation for Statistical Computing, Vienna, Austria). Mean values and standard deviations are reported. Differences between groups were tested by the Mann-Whitney test $(*)$ and mixed effect linear regression model (*). Associations between categorical variables were tested by Fisher's exact test (*). Primary hypotheses (results in Figure 1) were tested at the significance level $0.05\left(^{\star}\right)$. The problem of multiple comparisons within secondary hypotheses was counteracted by testing at the significance level $0.01{ }^{(*)}$.

\section{Results}

Seventy-seven adult patients, diagnosed with primary colorectal cancer, were initially enrolled in our prospective study. Two patients were excluded prior to data analysis (one due to later identified metastatic disease and one because of a severe postoperative haemorrhage). Five LAS patients were converted to open type surgery. These patients were moved to the OCS group for data analysis. The majority of patients underwent surgery due to adenocarcinoma and the rest of patients 

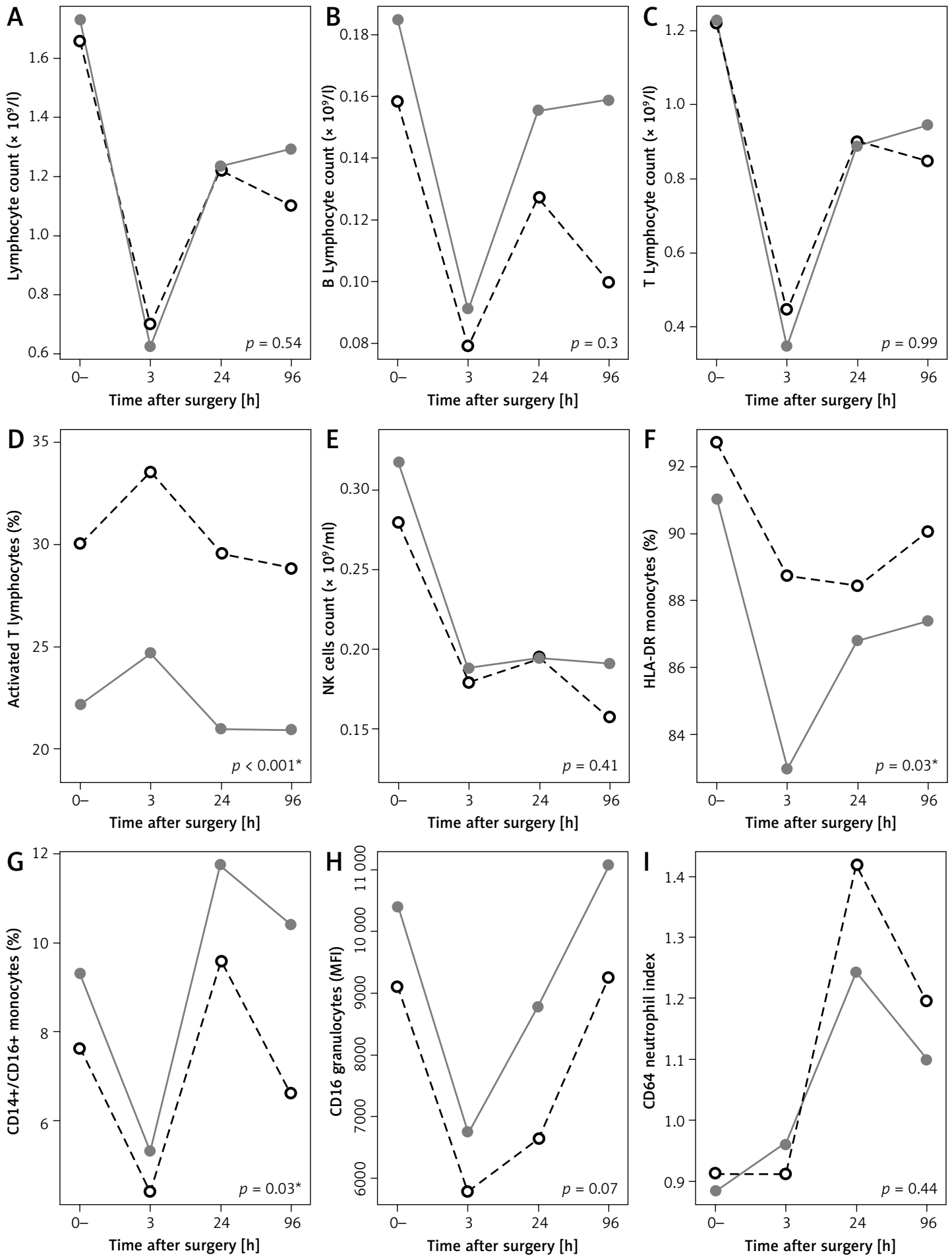

Figure 1. Mean response profiles for lymphocyte subpopulation levels at baseline (before surgery), after $3 \mathrm{~h}, 1 \mathrm{day}$ and 4 days after surgery, OCS group (dashed black line) and LAS (grey line)

due to adenomas. All resected specimens had microscopically negative resection margins (RO resections). Groups did not differ significantly in terms of age and gender, disease pathology, localization of the tumour, histological type, staging or the presence of vascular and perineural invasion (Table I). Short-term clinical outcomes for both groups of patients are summarised in Table II.

\section{Acute inflammatory response}

The dynamics of the observed acute inflammatory response, measured by values of total leucocyte count, CRP, PCT and ESR levels, are presented in Table III. The surgery type defined groups differ significantly in CRP values $(p=0.002)$, although the numbers of total leukocytes, CRP and PCT 
Table II. Summary of differences in short-term clinical outcomes between procedures

\begin{tabular}{|lccc|}
\hline Variable & \multicolumn{2}{c}{ Surgery type } & \multirow{2}{*}{ Value of $p$} \\
\cline { 2 - 3 } & Open $(n=34)$ & Laparoscopic $(n=41)$ & \\
\hline Duration of surgery [min] & $101(29)$ & $122(36)$ & $0.005^{* * *}$ \\
\hline Blood loss during surgery [ml] & $189(159)$ & $94(80)$ & $0.002^{* * *}$ \\
\hline Length of postoperative stay at hospital [days] & $8.5(3.1)$ & $7.3(1.5)$ & $0.02^{\star}$ \\
\hline Resumption of oral food intake [days] & $4.9(1.0)$ & $4.2(0.7)$ & $0.002^{* * *}$ \\
\hline $\begin{array}{l}\text { Duration of postoperative use of analgesic } \\
\text { therapy [days] }\end{array}$ & $4.1(1.3)$ & $3.6(1.2)$ & $0.08^{*}$ \\
\hline Postoperative complications & $5(15)$ & $2(5)$ & $0.23^{*}$ \\
\hline
\end{tabular}

Results presented as $n(\%)$ or mean (SD).

Table III. Postoperative acute inflammatory response

\begin{tabular}{|c|c|c|c|c|c|c|c|c|c|}
\hline \multirow[t]{4}{*}{ Variable } & \multicolumn{8}{|c|}{ Time, surgery type } & \multirow[t]{4}{*}{ Value of $p$} \\
\hline & \multirow{2}{*}{\multicolumn{2}{|c|}{$\begin{array}{c}t=0- \\
\text { Mean (SD) }\end{array}$}} & \multirow{2}{*}{\multicolumn{2}{|c|}{$\begin{array}{c}t=3 \mathrm{~h} \\
\text { Mean (SD) }\end{array}$}} & \multirow{2}{*}{\multicolumn{2}{|c|}{$\begin{array}{c}t=24 \mathrm{~h} \\
\text { Mean (SD) }\end{array}$}} & \multirow{2}{*}{\multicolumn{2}{|c|}{$\begin{array}{c}t=96 \mathrm{~h} \\
\text { Mean (SD) }\end{array}$}} & \\
\hline & & & & & & & & & \\
\hline & OCS & LAS & OCS & LAS & OCS & LAS & OCS & LAS & \\
\hline Total leucocytes $\left(10^{9} / \mathrm{l}\right)$ & $\begin{array}{c}7.0 \\
(2.4)\end{array}$ & $\begin{array}{c}6.5 \\
(2.1)\end{array}$ & $\begin{array}{l}12.5 \\
(4.1)\end{array}$ & $\begin{array}{l}11.9 \\
(2.7)\end{array}$ & $\begin{array}{l}11.2 \\
(4.2)\end{array}$ & $\begin{array}{l}10.0 \\
(2.5)\end{array}$ & $\begin{array}{c}7.7 \\
(2.3)\end{array}$ & $\begin{array}{c}6.7 \\
(2.1)\end{array}$ & 0.12 \\
\hline CRP $[\mathrm{mg} / \mathrm{l}]$ & $\begin{array}{c}13.2 \\
(30.4)\end{array}$ & $\begin{array}{c}5.7 \\
(9.6)\end{array}$ & $\begin{array}{c}14.1 \\
(23.1)\end{array}$ & $\begin{array}{c}8.8 \\
(13.8)\end{array}$ & $\begin{array}{l}109.0 \\
(42.4)\end{array}$ & $\begin{array}{c}67.9 \\
(49.3)\end{array}$ & $\begin{array}{c}74.1 \\
(44.7)\end{array}$ & $\begin{array}{c}54.8 \\
(47.4)\end{array}$ & $0.002^{* *}$ \\
\hline $\mathrm{PCT}[\mu \mathrm{g} / \mathrm{l}]$ & $\begin{array}{c}0.04 \\
(0.05)\end{array}$ & $\begin{array}{c}0.06 \\
(0.05)\end{array}$ & $\begin{array}{c}0.22 \\
(0.32)\end{array}$ & $\begin{array}{c}0.14 \\
(0.19)\end{array}$ & $\begin{array}{c}1.97 \\
(3.01)\end{array}$ & $\begin{array}{c}0.38 \\
(0.54)\end{array}$ & $\begin{array}{c}0.57 \\
(0.64)\end{array}$ & $\begin{array}{c}0.35 \\
(0.99)\end{array}$ & 0.23 \\
\hline $\mathrm{ESR}[\mathrm{mm} / \mathrm{h}]$ & $\begin{array}{c}24.3 \\
(19.6)\end{array}$ & $\begin{array}{c}18.2 \\
(19.0)\end{array}$ & $\begin{array}{c}15.6 \\
(17.5)\end{array}$ & $\begin{array}{c}11.8 \\
(12.0)\end{array}$ & $\begin{array}{c}24.4 \\
(21.7)\end{array}$ & $\begin{array}{c}17.0 \\
(18.0)\end{array}$ & $\begin{array}{c}45.5 \\
(27.0)\end{array}$ & $\begin{array}{c}35.5 \\
(20.1)\end{array}$ & 0.09 \\
\hline
\end{tabular}

were remarkably higher 4 days after surgery in patients who underwent an open colorectal procedure $\left(7.7 \times 10^{9} / \mathrm{l}, 74.1 \mathrm{mg} / \mathrm{l}, 0.57 \mu \mathrm{g} / \mathrm{l}\right.$ (OCS) vs. $6.710^{9} / \mathrm{l}, 54.8 \mathrm{mg} / \mathrm{l}, 0.35 \mu \mathrm{g} / \mathrm{l}$ (LAS), respectively).

\section{Changes in immunological parameters}

All lymphocyte subsets decreased considerably after both types of surgery. Mean response profiles of lymphocyte subpopulations and CD64

Table IV. Cytokine expression ( $\mathrm{ng} / \mathrm{ml}$ ) on the fourth day after surgery

\begin{tabular}{|lccc|}
\hline \multirow{2}{*}{ Parameter } & \multicolumn{2}{c}{ Surgery type } & Value of $p^{*}$ \\
\cline { 2 - 3 } & $\begin{array}{c}\text { Open } \\
(n=34)\end{array}$ & $\begin{array}{c}\text { Laparoscopic } \\
(n=41)\end{array}$ & \\
\cline { 2 - 3 } & Mean (SD) & Mean (SD) & \\
\hline IL-6 & $9.2(6.7)$ & $10.5(11)$ & 0.68 \\
\hline IL-8 & $9.4(5.0)$ & $6.9(4.0)$ & 0.02 \\
\hline IL-10 & $2.2(0.7)$ & $1.8(0.6)$ & 0.02 \\
\hline IL-1b & $2.4(0.6)$ & $2.2(0.8)$ & 0.19 \\
\hline IL-12p70 & $2.3(0.9)$ & $2.1(0.7)$ & 0.27 \\
\hline TNF & $2.4(0.9)$ & $1.9(0.9)$ & 0.02 \\
\hline
\end{tabular}

index at baseline and then $3 \mathrm{~h}, 24 \mathrm{~h}$ and 4 days after surgery are presented in Figure 1 . The between-groups test indicates that there were statistically significant differences between the OCS and the LAS group over time in the response of some lymphocyte subpopulations (activated $T$ cells $(p<0.001)$, HLA-DR monocytes $(p=0.03)$, CD14+/CD16+ monocytes $(p=0.03)$ ). Corresponding $p$-values for the effect of surgery type on responding variables are reported below interaction plots in Figure 1 and the significant values are denoted with an asterisk $\left({ }^{*}\right)$. We compared cytokine levels in both groups on the fourth day after surgery. Mean levels of observed cytokines IL-8, IL-10, IL-1b, IL-12p70 and TNF were slightly higher in the OCS group of patients $(9.4,2.2,2.4,2.3,2.4 \mathrm{ng} / \mathrm{ml}$ (OCS) vs. 6.9, 1.8, 2.2, 2.1, $1.9 \mathrm{ng} / \mathrm{ml}$ (LAS), respectively), but the differences between groups were not statistically significant (Table IV).

\section{Discussion}

The aim of our prospective nonrandomised clinical study was to elucidate the differences between changes in the immune responses induced by two different surgical approaches, laparoscopically assisted and open surgery, in patients with 
cancer of the colon or upper third of the rectum. In agreement with many other authors, we observed short-term clinical benefits for patients undergoing minimally invasive procedures compared to patients undergoing conventional surgery [20, $21,23]$. The LAS group had significantly less blood loss during surgery (mean values $94 \mathrm{ml}$ (LAS) vs. $189 \mathrm{ml}$ (OCS), $p=0.002$ ) and the length of postoperative hospital stay was shorter (mean difference 1.2 days, $p=0.02$ ). They also had earlier resumption of oral food intake (mean resumption time 4.2 days (LAS) vs. 4.9 days (OCS), $p=0.002$ ). Duration of postoperative analgesic therapy was shorter in the LAS group, although not statistically significantly so (mean duration 3.6 days (LAS) vs. 4.1 days (OCS), $p=0.08$ ).

\section{Postoperative acute inflammatory response}

We observed a considerably higher postoperative systemic inflammatory response in patients after OCS compared to LAS, which was especially evident on the fourth day after surgery, with importantly higher levels of CRP and total leukocyte counts in patients after OCS, compared to the LAS group $\left(74.1 \mathrm{mg} / \mathrm{l}, 7.7 \times 10^{9} / \mathrm{l}\right.$ (OCS) vs. $54.8 \mathrm{mg} / \mathrm{l}, 6.7 \times 10^{9} / \mathrm{l}$ (LAS), respectively). These findings are consistent with many previous studies $[20,21,23]$. It seems that a more prominent postoperative inflammatory response correlates with a greater amount of tissue damage in open colorectal surgery. A proinflammatory response is necessary for the initiation of repair mechanisms after injury, which is greater following conventional procedures, so it is not quite clear if these findings have any clinical significance. However, a greater inflammatory response leads to more adhesion formation. Furthermore, if the postoperative inflammatory response is too great, it can lead to organ dysfunction, so minimally invasive procedures seem to have an advantage over open surgery.

\section{Changes in immunological parameters}

Any surgical procedure causes temporary suppression of the immune system, with depleted numbers of $T$ and B lymphocytes and NK cells.

There was evident lymphopenia after both surgical procedures, which is consistent with other studies [12]. There were no significant differences in lymphocyte counts between the OCS and LAS group (Figure $1 \mathrm{~A}-\mathrm{C}$ ), although the mean values of $B$ and $T$ lymphocytes and total counts were lower in the OCS group 4 days after surgery $(0.1,0.85$ (OCS) vs. $0.16 \times 10^{9} /$, $0.95 \times 10^{9} /$ l (LAS), respectively). We also confirmed lower levels of NK cells, which are involved in preventing metastasis formation [29], in both groups (Figure 1 E).
Monocytes, which express HLA-DR, are a good marker of immunoparalysis since monocytes with down-regulated HLA-DR expression are not able to respond to inflammatory stimuli or present antigens [30]. A lower expression of HLA-DR on monocytes correlates with a higher incidence of infectious diseases and sepsis in trauma patients [31]. In our study we found an unexpected decrease in HLA-DR expression, which was significantly lower in the group of patients who underwent minimally invasive surgery, compared to patients who underwent conventional surgery (Figure $1 \mathrm{~F}, p=$ 0.03). Our observations of monocyte activation point to seemingly more pronounced monocyte suppression after laparoscopic procedures. These results are not consistent with findings of other studies [32, 33]. However, Menges et al. demonstrated that the duration of the surgical procedure has a significant influence on the postoperative expression of HLA-DR. Irrespective of the degree of surgical trauma involved, longer procedures resulted in significantly lower monocyte HLADR expression than shorter operations [34]. The conventional procedures in our study were significantly shorter than laparoscopically assisted procedures. Nevertheless, our results suggest the need for further research to be able to differentiate more specifically between the effects of surgical trauma and the procedure duration on the HLA-DR monocyte populations.

Blood monocytes expressing both the CD14+ and CD16+ antigen constitute a proinflammatory subtype, and exhibit features of tissue macrophages. Four days after surgery, levels of CD14+CD16+ in the OCS group were substantially lower than in the LAS group (6.62 \% (OCS) vs. $10.41 \%$ (LAS), Figure $1 \mathrm{G}, p=0.03$ ). Human neutrophils express a low-affinity receptor for IgG: FcRIIIb (CD16), which plays an important role in phagocytosis, cell-mediated cytotoxicity and the release of free radicals and proteolytic enzymes. A decrease in CD16 expression on granulocytes is a useful marker for disease severity in patients with sepsis [35]. The expression of CD16 on granulocytes was slightly lower in OCS patients one day after surgery (6647 mfi (OCS) vs. $8785 \mathrm{mfi}$ (LAS), Figure $1 \mathrm{H}, p=0.07$ ), which could also suggest some degree of immunoparalysis in these patients.

Postoperative immune disturbances, such as marked suppression in cell-mediated immunity following an excessive inflammatory response and especially depletion of HLA-DR, correlate with postoperative occurrence of sepsis and infectious complications [36, 37]. Since no differences were found in complication rates between the two groups in our study, we cannot draw any conclusions regarding the clinical significance of immunological disturbances. 
According to available literature on this topic, hand-sewn or stapled anastomoses have no known effect on systemic immune function or the systemic inflammatory response after surgery. The sewing material and stapling clips cause only a local tissue reaction within the anastomosis and have no known effect on the systemic inflammatory response and immune function after the operation [38].

\section{CD64 index}

CD64 is an FCRI receptor. It is a useful tool for diagnosing and assessing sepsis in patients and distinguishing between a septic or systemic inflammatory response [39-41]. Increased expression of CD64 molecules on neutrophils may be a good diagnostic indicator of the beginning of infection/sepsis [42]. It is almost not expressed in healthy human neutrophils. There has not been much research on the role of CD64 in early recognition of infectious complications in the postoperative period. Some trials have been done in orthopaedic and cardiovascular surgery, but not in abdominal surgery, which is in itself a contaminated or clean-contaminated procedure. Those studies have shown a greater increase in CD64 in patients who later developed an infectious complication [42]. When observing the neutrophil CD64 index, we found no significant differences between the two groups of patients $(p=0.44)$, but $24 \mathrm{~h}$ after surgery there was a considerable in crease in CD64 index in both groups (Figure $1 \mathrm{l}$ ). The maximum mean CD64 index in the LAS group (after $24 \mathrm{~h}$ ) was 1.24 and was on the threshold for sepsis (1.2), while the maximum mean index in the OCS group (after $24 \mathrm{~h}$ ) was 1.42 and was above that threshold (1.2). This implies that there may be a greater release of bacteria into the bloodstream following open type surgery compared to laparoscopic surgery. However, we did not observe any differences in the occurrence of postsurgical infectious complications or sepsis in any group. The role of CD64 in the early postoperative period should be determined on a larger sample with observed postoperative infections, especially since its role might be questionable due to a variety of postoperative disturbances in the immune system.

\section{Cytokine expression}

Mean values of the observed cytokines IL-8, IL-10, IL-1b, IL-12p70 and TNF were slightly higher in the OCS group of patients 4 days after surgery, although the differences were not statistically significant (Table IV). Higher levels of IL-10 are consistent with higher levels of immunosuppression in open surgical procedures, since high IL-10 serum concentrations have profound immunosuppressive actions [43]. The IL-8 and TNF levels correlate with a higher acute inflammatory response in patients who underwent a conventional surgical procedure. However, those two cytokines may also be involved in the antitumor response, so their role may be more universal. We found no differences in IL-6 production between the groups $(p=0.68)$, even though surgical trauma induces a significant release of IL-6, which triggers an acute-phase response. This may be because the peak of IL- 6 concentrations is present $3 \mathrm{~h}$ after surgery and it returns to preoperative values in a few days [12].

In conclusions, it seems that there are important advantages to minimally invasive surgery with regard to short-term clinical outcomes, which is consistent with other studies. Our patients had less blood loss, shorter duration of hospital stay and faster resumption of oral food intake after a minimally invasive procedure. Less tissue damage and lower surgical stress importantly contribute to faster recovery.

The clinical significance of immune disturbances following different surgical approaches has not yet been fully determined. No attempt to directly connect immunological parameters with clinical outcomes was attempted in our study, and there could be other factors contributing to clinical outcomes. Therefore, changes in observed immunological parameters may have more universal meaning. Further studies are needed to elucidate this topic.

Overall, our results show similar trends in post-surgical immunological disturbance between the two groups. Nonetheless, our data are of clinical interest - firstly, because we observed a divergent effect of different surgical approaches on the expression of HLA-DR on monocytes; and secondly, although our findings reflect a well-researched topic, they are the first results reported for Slovenia and are of great value in our local environment.

\section{Acknowledgments}

We thank the medical and nursing staff of the Department of Abdominal Surgery and the staff of the Department for Nuclear Medicine at University Medical Centre Ljubljana. We also thank the staff of the laboratory for flow cytometry at the Institute of Microbiology and Immunology, Medical Faculty Ljubljana, and the staff of the Institute for Biostatistics and Medical Informatics, Faculty of Medicine, University of Ljubljana, Slovenia for their valuable cooperation.

\section{Conflict of interest}

The authors declare no conflict of interest. 


\section{References}

1. Veldkamp R, Kuhry E, Hop WC, et al. Laparoscopic surgery versus open surgery for colon cancer: short-term outcomes of a randomised trial. Lancet Oncol 2005; 6: 477-84.

2. Chang GJ, Nelson H. Laparoscopic colectomy. Curr Gastroenterol Rep 2005; 7: 396-403.

3. Delaney CP, Kiran RP, Senagore AJ, Brady K, Fazio VW. Case-matched comparison of clinical and financial outcome after laparoscopic or open colorectal surgery. Ann Surg 2003; 238: 67-72.

4. Faiz O, Warusavitarne J, Bottle A, Tekkis PP, Darzi AW, Kennedy RH. Laparoscopically assisted vs. open elective colonic and rectal resection: a comparison of outcomes in English National Health Service Trusts between 1996 and 2006. Dis Colon Rectum 2009; 52: 1695-704.

5. King PM, Blazeby JM, Ewings P, et al. Randomized clinical trial comparing laparoscopic and open surgery for colorectal cancer within an enhanced recovery programme. Br J Surg 2006; 93: 300-8.

6. Schwenk W, Haase O, Neudecker J, Muller JM. Short term benefits for laparoscopic colorectal resection. Cochrane Database Syst Rev 2005; 3: CD003145.

7. Abraham NS, Young JM, Solomon MJ. Meta-analysis of short-term outcomes after laparoscopic resection for colorectal cancer. Br J Surg 2004; 91: 1111-24.

8. Clinical Outcomes of Surgical Therapy Study Group. A comparison of laparoscopically assisted and open colectomy for colon cancer. N Engl J Med 2004; 350: 2050-9.

9. Lacy AM, Garcia-Valdecasas JC, Delgado S, et al. Laparoscopy-assisted colectomy versus open colectomy for treatment of non-metastatic colon cancer: a randomised trial. Lancet 2002; 359: 2224-9.

10. Lacy AM, Delgado S, Castells A, et al. The long-term results of a randomized clinical trial of laparoscopy-assisted versus open surgery for colon cancer. Ann Surg 2008; 248: 1-7.

11. Vittimberga FJ Jr, Foley DP, Meyers WC, Callery MP. Laparoscopic surgery and the systemic immune response. Ann Surg 1998; 227: 326-34.

12. Evans C, Galustian C, Kumar D, et al. Impact of surgery on immunologic function: comparison between minimally invasive techniques and conventional laparotomy for surgical resection of colorectal tumors. Am J Surg 2009; 197: 238-45.

13. Lennard TW, Shenton BK, Borzotta A, et al. The influence of surgical operations on components of the human immune system. Br J Surg 1985; 72: 771-6.

14. Tang CL, Eu KW, Tai BC, Soh JG, MacHin D, SeowChoen F. Randomized clinical trial of the effect of open versus laparoscopically assisted colectomy on systemic immunity in patients with colorectal cancer. Br J Surg 2001; 88: 801-7.

15. Bolla G, Tuzzato G. Immunologic postoperative competence after laparoscopy versus laparotomy. Surg Endosc 2003; 17: 1247-50.

16. Sietses C, Beelen RH, Meijer S, Cuesta MA. Immunological consequences of laparoscopic surgery, speculations on the cause and clinical implications. Langenbecks Arch Surg 1999; 384: 250-8.

17. Carey PD, Wakefield CH, Thayeb A, Monson JR, Darzi A, Guillou PJ. Effects of minimally invasive surgery on hypochlorous acid production by neutrophils. Br J Surg 1994; 81: 557-60.

18. Ordemann J, Jacobi CA, Schwenk W, Stosslein R, Muller JM. Cellular and humoral inflammatory response af- ter laparoscopic and conventional colorectal resections. Surg Endosc 2001; 15: 600-8.

19. Brune IB, Wilke W, Hensler T, Holzmann B, Siewert JR. Downregulation of $T$ helper type 1 immune response and altered pro-inflammatory and anti-inflammatory $T$ cell cytokine balance following conventional but not laparoscopic surgery. Am J Surg 1999; 177: 55-60.

20. Wichmann MW, Huttl TP, Winter H, et al. Immunological effects of laparoscopic vs open colorectal surgery: a prospective clinical study. Arch Surg 2005; 140: 692-7.

21. Whelan RL, Franklin M, Holubar SD, et al. Postoperative cell mediated immune response is better preserved after laparoscopic vs open colorectal resection in humans. Surg Endosc 2003; 17: 972-8.

22. Shakhar G, Ben-Eliyahu S. Potential prophylactic measures against postoperative immunosuppression: could they reduce recurrence rates in oncological patients? Ann Surg Oncol 2003; 10: 972-92.

23. Huang C, Huang R, Jiang T, Huang K, Cao J, Qiu Z. Laparoscopic and open resection for colorectal cancer: an evaluation of cellular immunity. BMC Gastroenterol 2010; 10: 127.

24. Leung KL, Tsang KS, Ng MH, et al. Lymphocyte subsets and natural killer cell cytotoxicity after laparoscopically assisted resection of rectosigmoid carcinoma. Surg Endosc 2003; 17: 1305-10.

25. Han SA, Lee WY, Park CM, Yun SH, Chun HK. Comparison of immunologic outcomes of laparoscopic vs open approaches in clinical stage III colorectal cancer. Int J Colorectal Dis 2010; 25: 631-8.

26. Hewitt PM, Ip SM, Kwok SP, et al. Laparoscopic-assisted vs. open surgery for colorectal cancer: comparative study of immune effects. Dis Colon Rectum 1998; 41: 901-9.

27. Afessa B. Systemic inflammatory response syndrome in patients hospitalized for gastrointestinal bleeding. Crit Care Med 1999; 27: 554-7.

28. Haga Y, Beppu T, Doi K, et al. Systemic inflammatory response syndrome and organ dysfunction following gastrointestinal surgery. Crit Care Med 1997; 25: 1994-2000.

29. Langers I, Renoux VM, Thiry M, Delvenne P, Jacobs N. Natural killer cells: role in local tumor growth and metastasis. Biologics 2012; 6: 73-82.

30. Hoflich C, Docke WD, Meisel C, Volk HD. Regulatory immunodeficiency and monocyte deactivation. Assessment based on HLA-DR expression. Clin Appl Immunol Rev 2002; 2: 337-44.

31. Hershman MJ, Cheadle WG, Wellhausen SR, Davidson PF, Polk HC Jr. Monocyte HLA-DR antigen expression characterizes clinical outcome in the trauma patient. $\mathrm{Br}$ J Surg 1990; 77: 204-7.

32. Wu FP, Sietses C, von Blomberg BM, van Leeuwen PA, Meijer S, Cuesta MA. Systemic and peritoneal inflammatory response after laparoscopic or conventional coIon resection in cancer patients: a prospective, randomized trial. Dis Colon Rectum 2003; 46: 147-55.

33. Veenhof AA, Sietses C, von Blomberg BM, et al. The surgical stress response and postoperative immune function after laparoscopic or conventional total mesorectal excision in rectal cancer: a randomized trial. Int J Colorectal Dis 2010; 26: 53-9.

34. Menges P, Kessler W, Kloecker C, et al. Surgical trauma and postoperative immune dysfunction. Eur Surg Res 2012; 48: 180-6.

35. Ono S, Tsujimoto H, Matsumoto A, Ikuta S, Kinoshita M, Mochizuki H. Modulation of human leukocyte antigen-DR on monocytes and CD16 on granulocytes in pa- 
tients with septic shock using hemoperfusion with polymyxin B-immobilized fiber. Am J Surg 2004; 188: 150-6.

36. Kimura F, Shimizu H, Yoshidome H, Ohtsuka M, Miyazaki M. Immunosuppression following surgical and traumatic injury. Surgery Today 2010; 40: 793-808.

37. Cheadle WG, Hershman MJ, Wellhausen SR, Polk HC Jr. HLA-DR antigen expression on peripheral blood monocytes correlates with surgical infection. Am J Surg 1991; 161: 639-45.

38. McGregor JR, Akyol AM, Murray GD, Galloway DJ. Comparison of manually constructed and stapled anastomoses in colorectal surgery. Ann Surg 1995; 221: 176-84.

39. Fjaertoft G, Hakansson LD, Pauksens K, Sisask G, Venge P. Neutrophil CD64 (FcgammaRI) expression is a specific marker of bacterial infection: a study on the kinetics and the impact of major surgery. Scand J Infect Dis 2007; 39: 525-35.

40. Groselj-Grenc M, Ihan A, Pavcnik-Arnol M, Kopitar AN, Gmeiner-Stopar T, Derganc M. Neutrophil and monocyte CD64 indexes, lipopolysaccharide-binding protein, procalcitonin and C-reactive protein in sepsis of critically ill neonates and children. Intensive Care Med 2009; 35: 1950-8.

41. Li S, Huang X, Chen Z, et al. Neutrophil CD64 expression as a biomarker in the early diagnosis of bacterial infection: a meta-analysis. Int J Infect Dis 2013; 17: e12-23.

42. Daryapeyma A, Pedersen G, Laxdal E, et al. Neutrophil CD64 as a marker for postoperative infection: a pilot study. Eur I Vasc Endovasc Surg 2009; 38: 100-3.

43. Moore KW, de Waal Malefyt R, Coffman RL, O'Garra A. Interleukin-10 and the interleukin-10 receptor. Annu Rev Immunol 2001; 19: 683-765. 